НИКОЛАЕВ Владимир Константинович - кандидат экономических наук, проректор по развитию цифровых технологий Российской таможенной академии (105275, Россия, г. Москва, np-кт Буденного, 51, корп. 6; nvk64@list.ru)

НИКОЛАЕВ Константин Алексеевич - кандидат философских наук, доцент кафедры государственного и муниципального управления Балаковского филиала Российской академии народного хозяйства и государственной службы при Президенте РФ (413865, Россия, Саратовская обл., г. Балаково, ул. Чапаева, 107; konstantin.nikolaev.49@mail.ru)

\title{
К ВОПРОСУ О СОДЕРЖАНИИ ТЕРМИНА «ГОСУДАРСТВО»
}

Аннотация. В статье анализируются широкий и узкий подходы к толкованию сущности термина «государство». Согласно авторской точке зрения, государство можно трактовать как организованное территориальное сообщество граждан, которое в целях обеспечения своего временно́го и пространственного воспроизводства, своего жизнеобеспечения, социально-экономического и духовного развития формирует и (или, в случае отсутствия народовластия) поддерживает политический механизм, регулирующий общественные отношения и объединяющий большинство людей, обеспечивая баланс социальных интересов посредством как достижения общественного согласия, так и легитимного принуждения. При этом под политическим механизмом понимается то, что в политологии или в теории государства и права вкладывается в содержание термина «политическая система».

Ключевые слова: государство, политический механизм, политическая система, признаки государства.

$\Gamma$ осударство как сложный, многомерный социальный феномен, подвергаемый теоретическому анализу с позиций различных отраслей научного знания, до настоящего времени порождает разнообразные подходы с точки зрения как толкования процесса его возникновения, так и понимания его сущности. Многомерность государства, его многоаспектное проявление в общественной жизни и в человеческом сознании объясняется тем, что государство одновременно предстает как:

- целостное сообщество людей, объединенных и организованных посредством заданной системы общественных отношений, структурированное, упорядоченное и способное, в той или иной мере, к эффективному функционированию и развитию;

- территориальное образование, объединяющее людей, обладающих разными этническими, религиозными, социальными, демографическими характеристиками через институт гражданства, нормативно предписывающий обязательства как государства перед своими гражданами, так и граждан перед государством, а также вступающее во взаимоотношения с иными территориальными образованиями - странами и их объединениями;

- механизм закрепления воли большинства, отражающей общие потребности и интересы, в т.ч. посредством нормотворческой деятельности, и ее реализации в повседневной общественной жизни;

- система государственных и иных властно-управленческих структур, в рамках которых должностные лица, преимущественно на профессиональной основе, осуществляют властно-управленческую деятельность по обеспечению функционирования данного человеческого сообщества, его политического, социально-экономического, духовного развития [Атаманчук 2004: 65-69].

Тем не менее единого толкования того, что же собой представляет государство на настоящий момент, нет ни в научной литературе, ни в международном праве, ни в политической практике и публицистике [Чернышов 2017: 64].

В российской традиции сформировались два основных подхода к толкова- 
нию термина «государство»: широкое - как некая коллективность, общность, и узкое - как совокупность институтов власти, властный аппарат [Черепанов 2019: 132].

При широком толковании государство есть политическое и правовое объединение граждан, высшая форма организации человеческих сообществ, политический союз людей, которые подчинены единой верховной власти, для обеспечения общих интересов, защиты прав и свобод человека [Зеркин, Игнатов 2007: 30; Кнорринг 2006: 13], политическая форма организации жизни общества, которая складывается как результат возникновения и деятельности публичной власти - особой управляющей системы, руководящей основными сферами общественной жизни и опирающейся в случае необходимости на силу принуждения» [Теория государства... 2011: 727]. Это «политическая целостность, созданная национальной или многонациональной общностью людей на определенной территории, где с помощью политической элиты, монополизирующей власть, поддерживается юридический порядок, включая законное право на применение насилия» [Василенко 2013: 81-82].

При узком толковании государство выступает как публичная и легитимная властная сила общества, система особого типа социальных институтов, которые организуют политическую власть [Атаманчук 2004: 69; Зеркин, Игнатов 2007: 31], единая политическая, властная организация общества, которая распространяет свою власть на всю территорию страны и ее население, обладает государственным суверенитетом и располагает специальным аппаратом управления и принуждения, издавая нормативные акты, устанавливающие обязательный для всех правовой порядок [Теория государства... 2011: 149; Теория государства... 2014: 74]. В современных условиях, связанных с масштабными процессами цифровизации, становления и бурного развития информационного общества, в рамках узкого подхода к толкованию рассматриваемого термина сформировалось представление о государстве как платформе, которая выступает основой для «представления государства в качестве пространства для гражданской активности», а также технологическим инструментом и базой «для использования больших данных в различных приложениях», причем фактически речь идет об электронном правительстве и способе сделать его еще более открытым, ответственным и чувствительным к потребностям людей [Сморгунов 2019: 10].

Наряду с этим встречаются своего рода компромиссные толкования содержания термина «государства». Наиболее ярко это выражено у В.Е. Чиркина, который считает, что государство - «это политическое сообщество граждан и одновременно универсальная политическая организация, обладающая особой (суверенной государственной) властью и специализированным аппаратом регулятивного воздействия на общество (в том числе путем легализованного принуждения), выполняющая общие для общества задачи, выражающая в процессе социального арбитража прежде всего волю доминирующего социального слоя, но учитывающая в определенной мере интересы других слоев» [Чиркин 2008: 145-146]. Близка к такому подходу и позиция Э. Хейвуда, согласно которому государство - это «политическая организация, обладающая суверенной властью в пределах определенной территории и отправляющая ее посредством постоянно действующих институтов», считающихся «публичными, так как отвечают за организацию коллективной жизни в обществе и финансируются из общественных средств» [Хейвуд 2005: 109].

Тем не менее, как отмечает А.Г. Чернышов, «все или почти все существующие определения государства, равно как и реальная практика, являются определениями государственной власти» [Чернышов 2017: 65].

Следует отметить, что узкое толкование термина «государство», фактически 
отождествляющее его с государственной властью, невольно приводит к относительной отделенности государства от общества, народа, его населяющего: «в современных условиях государство не способно стать народом, оставаясь государством в сегодняшнем понимании» [Васильев, Зенин 2019: 4], а то и к прямому противопоставлению народа и государства, рассматриваемых как две различные и противоположные сущности [Черепанов 2019: 132]. В связи с таким толкованием и возникает, например, активно обсуждаемая в литературе проблема взаимоотношения государства и общества, государства и гражданского общества. Анализируя вопросы данных взаимоотношений, Ю.А. Красин, например, пишет о том, что «государство вынуждено считаться с гражданским обществом», которое имеет возможность влиять на принятие властных решений, оказывать давление на власть и контролировать ее» [Красин 2013: 51-52], а С.Н. Кожевников, в свою очередь, отмечая как единство, так и различия между государством и гражданским обществом, констатирует, что «гражданское общество - это система самостоятельных и независимых от государства общественных институтов и отношений» [Теория государства... 2014: 194]. Более того, В.К. Бабаев, рассматривая проблемы правотворчества выделяет, например, такой его принцип, как народный характер и пишет: «...государство, стремящееся стать правовым, в своей законодательной деятельности должно быть тесно связано со своим народом» [Теория государства... 2014: 400]. Да и А.Н. Головистикова пишет: «Государство проявляет заботу об обществе или, напротив, паразитирует или даже сокрушает общественный организм» [Теория государства... 2011: 410].

Именно такая возможность отделения, даже противопоставления государства и общества, граждан, его составляющих, - «главная драма русской жизни - это пропасть между человеком и государством» [Чернышов 2017: 59], обусловливает не просто ограниченность, а нецелесообразность использования такого подхода к определению рассматриваемого термина. Говоря о государстве, оправданно обращаться к организованному определенным образом человеческому сообществу, осознающему обобщенные потребности в рамках конкретной территории, способному организовывать самое себя, формируя институт своего развития [Чернышов 2017: 65]. Не случайно, анализируя сущность народовластия или народного суверенитета, например, И.А. Умнова подчеркивает, что народ - «не простая совокупность граждан конкретного государства, обладающих политическими, в том числе избирательными правами, а сообщество граждан, объединенных общегосударственными или общенациональными интересами» [Умнова, Алешкова 2012: 149]. В этом плане представляется интересным предложение И.И. Кравченко трактовать государство как «совокупность людей, занимающих принадлежащую им территорию, организованная политической системой, сформированной этой общностью (обществом) или ее доминирующей частью (сообществом)», хотя в целом и признает, что государство и общество соотносятся в рамках субъект-объектных отношений [Кравченко 2007: 20-21]. В свою очередь, В.А. Черепанов полагает, что «государство - это не надстройка над обществом, а публично организованное общество, публично-властным образом организованный народ (государственно организованный народ, “коллективный гражданин”)» [Черепанов 2019: 132]. Да и в зарубежной литературе, как свидетельствует В.А. Гуторов, встречается точка зрения, согласно которой государство есть соединение постоянных жителей определенной территории и правительства [Гуторов 2014: 96]. Э. Хейвуд замечает, что государство включает в свои границы все институты публичной сферы и охватывает всех членов общества в качестве своих граждан, в то время как правительство есть лишь часть государства [Хейвуд 2005: 109]. 
И еще одно важное замечание. При рассмотрении вопросов, связанных с сущностью государства, исследователи обращают внимание на то, что «через его структуры и механизмы формируется и закрепляется всеобщая воля» [Атаманчук 2004: 67], что государство есть «становой институт определенной системы, институт развития» [Чернышов 2017: 65], «орудие организационного угнетения... инструмент, удерживающий людей от междоусобиц» [Васильев, Зенин 2019: 5]. Иначе говоря, представляется возможным говорить о том, что государство, рассматриваемое прежде всего как система социальных институтов, выражающих государственную власть, властная сила общества, олицетворяемая государственными органами, управляющая система, по сути своей есть некий политический инструмент, политический механизм, позволяющий территориальному сообществу, выстраивая и регулируя общественные отношения, обеспечивать свое временно́е и пространственное воспроизводство, социально-экономическое и духовное развитие, объединяя людей, обеспечивая баланс социальных интересов посредством достижения общественного согласия. В Российской Федерации такое территориальное сообщество граждан - многонациональный народ, т.е. «не отделенная от государства сущность, а неразложимая далее структурная единица государственности» [Черепанов 2019: 132], как отмечено в преамбуле Конституции РФ. Он соединен скрепами общей судьбы на своей родной земле, сохранением исторически сложившегося государственного единства, памятью предков, передавших нынешнему и будущим поколениям любовь и уважение к Отечеству, веру в добро и справедливость на основе общепризнанных принципов равноправия, суверенной государственности и незыблемости демократической основы существования российского общества.

Исходя из этого, предлагается рассматривать государство как такое организованное территориальное сообщество граждан, которое в целях обеспечения своего временно́го и пространственного воспроизводства, своего жизнеобеспечения, социально-экономического и духовного развития формирует и (или, в случае отсутствия народовластия) поддерживает политический механизм, регулирующий общественные отношения, объединяющий большинство людей, обеспечивая баланс социальных интересов посредством как достижения общественного согласия, так и легитимного принуждения.

Под политическим механизмом в данном случае предлагается понимать то, что вкладывается в содержание термина «политическая система»: в политологии - это целостная совокупность государственных, политических, общественных организаций и объединений, политических и правовых норм, принципов, в рамках которых организуется и реализуется политическая власть в обществе [Политология 2013: 219]; в теории государства и права - «совокупность институтов государственно-организованного общества», которые осуществляют «политические функции на основе идейных установок, принципов, политических и правовых норм, соответствующих форм сознания и культуры» в целях выстраивания и совершенствования отношений между публичной властью, общественными объединениями и гражданами [Теория государства... 2014: 152].

При рассмотрении вопросов, связанных с толкованием содержания термина «государство», как правило, указывают перечень основных признаков или характерных черт государства как политико-территориальной организации, посредством которых, собственно, и предлагается определять содержание рассматриваемого термина [Теория государства... 2014: 70]. Причем следует подчеркнуть: именно признаков, или черт, присущих государству, а не его элементов. О спорности традиционного представления государства в виде совокупности таких элементов, как территория, население, государственная власть и т.П., 
справедливо говорит В.А. Черепанов [Черепанов 2019: 130-131]. Что же касается наиболее очевидных основных признаков, или характерных черт такого феномена, как государство, то к таковым представляется целесообразным отнести:

- наличие территории как ограниченного государственными границами пространства, в пределах которого распространяется суверенитет государства и государственные органы осуществляют свои полномочия;

- наличие населения как организованного территориального сообщества людей, объединенных юридическим институтом гражданства, проживающих на территории государства (в некоторых источниках первые два признака объединяют в один - «территориальное деление населения» [Теория государства... 2011: 149], «территориальная организация населения» [Теория государства... 2014: 70] или «территориальная организация власти и населения» [Охотский 2015: 323]);

- функционирование политического механизма, и прежде всего - института (аппарата) государственной власти и управления, обеспечивающего способность, возможность и право определять общественное поведение и деятельность населения, проживающего на территории государства, в т.ч. с помощью легитимного права на применение насилия, которое выражается в возможности наложения уголовного наказания, административных, имущественных и иных санкций (иногда этот признак определяют как «легитимно узаконенную властную силу» [Охотский 2015: 323]);

- действие права как системы общеобязательных законодательно закрепленных правил поведения, которая является одним из важнейших средств управления;

- взимание налогов как общеобязательных и безвозмездных платежей в заранее установленных размерах и в определенные сроки, необходимых для содержания публичных органов власти и управления, поддержания жизнедеятельности общества (иногда данный признак определяют как систему налогов и займов [Теория государства... 2011: 149], государственную казну, связанную с налогообложением и взиманием налогов [Теория государства... 2014: 70]);

- государственный суверенитет как международную правосубъектность, способность государства проводить независимую внешнюю и внутреннюю политику, обеспечивать верховенство государственной власти на всей территории страны и независимость государства на международной арене, как способность защищать страну, четко выражать и отстаивать общенациональные ценности и интересы как внутри страны, так и на международной арене, принимать «ответственность за судьбы развития мировых процессов в созидательном русле» [Чернышов 2017: 58];

- вооруженные силы, которые выполняют функцию защиты государства от внешних угроз, защиты государственного суверенитета.

В заключение хочется подчеркнуть следующее. В предлагаемой дефиниции термина «государство» ключевым выступает не столько политический механизм, сколько территориальное сообщество граждан, или иначе, как определяет В.Е. Чиркин, территориальный публичный коллектив как объединение людей, имеющих общий или публичный характер, существование которого обусловлено прежде всего необходимостью своего жизнеобеспечения, а не идейными, политическими взглядами, не видами деятельности и не определенными склонностями [Чиркин 2008: 36]. Ключевая роль такого сообщества объясняется тем, что при ослаблении по каким-либо причинам скрепляющих его взаимосвязей, тем более при их распаде, политический механизм перестает эффективно функционировать, государство как территориальное сообщество начинает терять свою суверенность и тогда либо государство как таковое пере- 
стает существовать, либо политический механизм начнет использовать чрезвычайные меры, в т.ч. диктатуру как форму принудительного соединения отдельных индивидов и их объединения в квазисообщество, либо территориальное сообщество тем или иным способом качественно переформатирует потерявший в его глазах легитимность ранее сформированный политический механизм.

\section{Список литературы}

Атаманчук Г.В. 2004. Теория государственного управления: курс лекций. 2-е изд., доп. М.: Омега-Л. 584 с.

Василенко И.А. 2013. Государственное и муниципальное управление: учебник для бакалавров. 5-е изд., перераб. и доп. М.: Юрайт. 495 с.

Васильев С.А., Зенин С.С. 2019. Народ и государство: конституционно-правовая парадигма взаимодействия. - Государственная власть и местное самоуправление. № 10. С. 3-8.

Гуторов В.А. 2014. К вопросу о происхождении государства: парадоксы и аномалии современных интерпретаций. - Полис. Политические исследования. № 3. C. 91-110.

Зеркин Д.П., Игнатов В.Г. 2007. Основы теории государственного управления: курс лекций. 3-е изд., доп. и перераб. М.: ИКЦ «МарТ»; Ростов н/Д: ИЦ «MapT». 544 c.

Кнорринг В.И. 2006. Основы государственного и мунищипального управления: учебник. 3-е изд., доп. М.: Экзамен. 477 с.

Кравченко И.И. 2007. Государство и общество. - Вопросы философии. № 7. C. 19-35.

Красин Ю.А. 2013. Государство и общество: сдвиги во властном поле. - Полис. Политические исследования. № 5. С. 51-58.

Охотский Е.В. 2015. Теория и механизмы современного государственного управления. В 2 т.: учебник и практикум для бакалавриата и магистратуры. 2-е изд., перераб. и доп. М.: Юрайт. Т. 1. 479 с.

Политология: учебник для бакалавров (под ред. И.Е. Тимерманиса). М.: Юрайт. 701 с.

Сморгунов Л.В. 2019. Партисипаторная государственная управляемость: платформы и сотрудничество. - Власть. Т. 27. № 5. С. 9-19.

Теория государства и права: учебник. 2-е изд., перераб. и доп. (под ред. А.С. Пиголкина, Ю.А. Дмитриева). 2011. М.: Юрайт. 743 с.

Теория государства и права: учебник для бакалавров. 3-е изд., перераб. и доп. (под ред. В.К. Бабаева). 2014. М.: Юрайт. 715 с.

Умнова И.А. Алешкова И.А. 2012. Конституционное право РФ: учебник для бакалавров. М.: Юрайт. 578 с.

Хейвуд Э. 2005. Политология: учебник для студентов вузов (пер. с англ.; под ред. Г.Г. Водорезова, В.Ю. Бельского). М.: ЮНИТИ-ДАНА. 544 с.

Черепанов В.А. 2019. Народ и государство: о доктринальном толковании конституционной модели. - Журнал российского права. № 1. С. 129-141.

Чернышов А.Г. 2017. Современное государство: последний левиафан, фантом или мессия? - Власть. Т. 25. № 5. С. 57-67.

Чиркин В.Е. 2008. Система государственного и мунищипального управления: учебник. 3-е изд., перераб. М.: Норма. 448 с. 
NIKOLAEV Vladimir Konstantinovich, Cand.Sci. (Econ.), Vice-rector for Digital Development at the Russian Customs Academy (bld. 6, 51 Budennogo Ave, Moscow, Russia, 105275; nvk64@list.ru)

NIKOLAEV Konstantin Alekseevich, Cand.Sci. (Philos.), Associate Professor at the Chair of State and Municipal Administration, Balakovo Branch of the Russian Presidential Academy of National Economy and Public Administration (RANEPA) (107 Chapaeva St, Balakovo, Saratov Region, Russia, 413865; konstantin.nikolaev.49@mail.ru)

\title{
ON THE MEANING OF THE TERM «STATE»
}

\begin{abstract}
The article analyzes broad and specific approaches to the interpretation of the term "state» and points out the restrictions of such interpretation in the term's narrow sense - solely as a system of authority institutions, administrative apparatus, and legitimate power of authorities. The authors express an opinion that state may be seen as such an organized territorial community of citizens which pursue the goal of securing their temporal and spatial reproduction, their necessities of life, as well as social, economic and cultural development. It forms or (in a non-democracy) support the political framework that regulates social relations and unites the majority of people, while ensuring a balance of social interests by both achieving public consent and legitimate enforcement. The authors show that at the same time the political framework is the composition of state, political and public organizations that perform their political enforcement and administrative activities on the base of certain principles and values. To make such interpretation of the term "state» clearer, the paper provides a list of the basic features of the state: the presence of territory and population as a community of citizens, an apparatus of public authority and administration, legal and tax systems, with actual national sovereignty and armed forces available.
\end{abstract}

Keywords: state, political framework, political system, attributes of the state

ЮСУПОВА Гурия Ислангараевна - доктор философских наук, главный научный сотрудник Регионального иентра этнополитических исследований Дагестанского федерального исследовательского центра Российской академии наук (367025, Россия, Республика Дагестан, г. Махачкала, ул. М. Гаджиева, 45; huria@list.ru)

\section{КОНЦЕПТУАЛИЗАЦИЯ КАТЕГОРИИ «ЭТНОПОЛИТИЧЕСКАЯ БЕЗОПАСНОСТЬ» В СОВРЕМЕННОМ ПОЛИТОЛОГИЧЕСКОМ ДИСКУРСЕ}

\begin{abstract}
Аннотация. Автор рассматривает институционализацию категории «этнополитическая безопасность» для анализа безопасности этнополитического пространства Северо-Кавказского региона с применением исследовательских возможностей институционального, системного подходов, принципа междисциплинарности. В статье предлагается авторское определение этнополитической безопасности, формулируются рекомендации, направленные на повышение эффективности этнополитической безопасности в условиях современных модернизационных вызовов и угроз.
\end{abstract}

Ключевые слова: национальная безопасность, Северный Кавказ, этнополитическая безопасность, конфликт, этнополитические отношения, риски и угрозы

A ктуальность темы исследования обусловлена расширением интереса к изучению различных аспектов национальной и региональной безопасности. Сегодня национальная безопасность является доминантным направлением формирования общероссийской гражданской идентичности, сохранения целостности российского социума, надежным инструментом устойчивого развития полиэтноконфессионального государства. В современном научном дискурсе актуализировались проблемы глобальной безопасности. В качестве угроз 